Portland State University

PDXScholar

1977

\title{
A Descriptive Study of the Pragmatic Issues in Obtaining an Abortion Among Sixty-five Women at Lovejoy Specialty Hospital, Portland, Oregon
}

\author{
Barbara E. Bordner \\ Portland State University \\ Wendy Green \\ Portland State University \\ Susie Milberg \\ Portland State University
}

Follow this and additional works at: https://pdxscholar.library.pdx.edu/open_access_etds

Part of the Medicine and Health Commons, and the Social Work Commons Let us know how access to this document benefits you.

\section{Recommended Citation}

Bordner, Barbara E.; Green, Wendy; and Milberg, Susie, "A Descriptive Study of the Pragmatic Issues in Obtaining an Abortion Among Sixty-five Women at Lovejoy Specialty Hospital, Portland, Oregon" (1977). Dissertations and Theses. Paper 2582.

https://doi.org/10.15760/etd.2579

This Thesis is brought to you for free and open access. It has been accepted for inclusion in Dissertations and Theses by an authorized administrator of PDXScholar. Please contact us if we can make this document more accessible: pdxscholar@pdx.edu. 
(

A DESCRIPTIVE STUDY OF THE PRAGMATIC ISSUES

IN OBTAINING AN ABORTION AMONG SIXTY-FIVE WOMEN AT LOVEJOY SPECIALTY HOSPITAL, PORTLAND, OREGON ${ }^{\prime}$

by

BARBARA E. BORDNER

WENDY GREEN

SUSIE MILBERG

A report submitted in partial fulfillment of the requirements for the degree of

MASTER OF SOCIAL WORK

Portland State University

1977 
APPROVED :

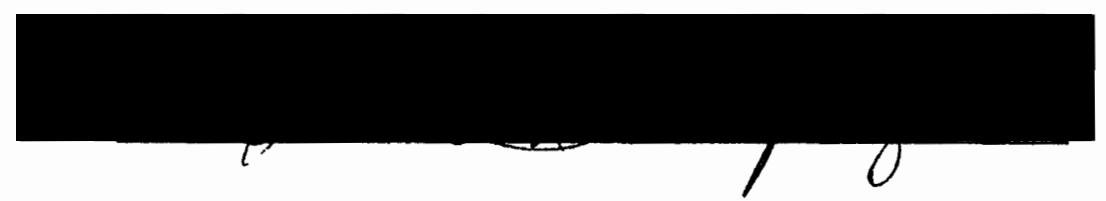




\section{ACKNOWLEDGEMENTS}

We wish to acknowledge and thank Alene Klass, director of Lovejoy Specialty Hospital, the pregnancy counselors, Marian Ayerza, Assistant Professor, School of Social Work, Portland State University, and Nancy Koroloff, Assistant Professor, School of Social Work, Portland State University, for their time, assistance, and critical readings of the various drafts of the manuscript.

Our special thanks and appreciation are extended to the seventy women who were the subjects of our research and whose cooperation made this study possible. 
TABLE OF CONTENTS

PAGE

ACKNOWLEDGEMENTS

LIST OF TABLES

iv

INTRODUCTION

REVIEW OF LITERATURE

Part I

Part II.

METHODOLOGY

Choice of Agency

Description of Lovejoy Specialty Hospital . . . 16

Choice of Respondent Population . . . . . . . 17

Instrument Development and Design . . . . . . 18

Pretest. . . . . . . . . . . . . . 19

Instrument Administration . . . . . . . . . 19

FINDINGS . . . . . . . . . . . . . . . . . . 21

CONCLUSIONS AND IMPLICATIONS . . . . . . . . . . . . 33

RECOMMENDATIONS . . . . . . . . . . . . . . . . . 43

LIST OF FOOTNOTED REFERENCES . . . . . . . . . . . . 46

SELECTED BIBLIOGRAPHY . . . . . . . . . . . . . . 50

APPENDIX . . . . . . . . . . . . . . . . . . 53 


\section{LIST OF TABLES}

TABLE

PAGE

I Age of Respondents . . . . . . . . . . . . 21

II Occupation of Respondents . . . . . . . . 22

III Educational Background of Respondents . . . 23

IV Living Arrangements When Respondent Learned of Pregnancy . . . . . . . . 24

V Number of Children . . . . . . . . . . 24

VI Feelings after the Abortion . . . . . . 25

VII Services Respondents Would Use if Provided . . . . . . . . . . . 26

VIII Source of Birth Control Information . . . . 27

IX Options Respondents Knew Enough About

to Personally Consider . . . . . . . 29

$X$ Source of Abortion Information Prior to

Contact with Lovejoy Specialty

Hospital . . . . . . . . . . . . 29

XI Sources Through Which Respondents Heard

about Lovejoy Specialty Hospital . . . 30

XII Difficulty Experienced by Respondents

in Paying for Abortion . . . . . . . . 


\section{INTRODUCTION}

In view of the current diversity of public opinion concerning the legalization of abortion in this country, it appears timely that a study of the pragmatic issues faced in obtaining an abortion be undertaken. The researchers see this as a step toward narrowing the lag between the enactment of the abortion law and the delivery of services that allow the right of abortion to be an accessible choice for women.

There has been a change in public opinion, regarding the right of abortion, only recently. In 1960, a public opinion poll showed that fewer than 15 percent of the population believed that women have the right to have an abortion if they so choose. In 1969, that figure rose to 40 percent and in 1971 over 50 percent of the population polled believed abortion to be a legal right for women, as stated by Nancy Brown in Abortion; Women's Fight for the Right to Choose.

Several factors led toward attitude changes:

(1) The rise of the Women's Liberation Movement advocating women's rights.

(2) Improvements in medical technology and hospital facilities. 
(3) An increasing emphasis on zero population growth in the United States.

(4) In general, a liberalization of social attitudes regarding sex, morality, and family.

These factors have played a major role in the struggle to legalize abortion in this country. However, the researchers surmised the following problems still exist that reflect this lag between the enactment of the law to legalize abortion and the delivery of safe, expedient, and affordable abortion services.

These problematic issues are as follows:

(1) Studies of abortion for the most part have addressed themselves to the issues of emotional and psychological implications of women who have had an abortion.

(2) It cannot be assumed that all women have avai1able to them, sufficient and accessible abortion information and knowledgeable access of those services so that the pragmatic issues of what choices, what procedures, where, when, and who will perform the service, and how affordable and by what means can the procedure be paid for, are equally known.

(3) Birth control information and dispensation of methods are not widely available to all women.

The above issues will be further developed in the literature review. 
It is, therefore, the contention of the researchers that the following assumptions are true:

(1) All women need access to the present full range of information pertaining to the availability of birth control methods and abortion procedures.

(2) Access to the current information about procedures, effects, and facilities which are capable of legally performing an abortion that is affordable, need to be emphasized in further studies and by the community at large.

This study has been designed to ascertain which problems, if any, a woman has in arranging for and financing a legal abortion once she has decided to terminate a pregnancy.

The researchers have personal motivations in carrying through this study. Out of a common interest in women and a concern for obtaining services for them coupled with the direct experience of one member, Susie Milberg, in abortion counseling, this descriptive study was formulated. 
REVIEW OF LITERATURE

In reviewing the literature on abortion, it was found that there has been a relatively limited number of studies and articles published on the pragmatic issues of available information and accessibility in obtaining a legal abortion for women.

Studies have, in the past, conducted research on the emotional and psychological effects before and after abortion, $1,2,3,4,5,6,7,8$ and the advantages and disadvantages of therapeutic abortions from moral, medical, and legal viewpoints, 9,10,11,12 historical antecedents to present-day abortion laws, 13,14,15 and the decreases in mortality rates of expectant mothers. 16,17

Due to the limited volume of literature and studies conducted on information and services available to women who have decided to have an abortion, this literature review will consist of two parts. Part I will be a discussion of: a definition of abortion procedures, the evolution in legalization of abortion, and a discussion of the nonpragmatic factors that influence the decision for a therapeutic abortion by women. Part II of the review will be a discussion of: the available literature and current studies dealing with abortion and birth control accessibility. 


\section{PART I}

The term abortion, in this study, refers to the . . removal of a developing infant (at first an impregnated egg--later called an embryo; then after three months, a fetus) from the female womb (uterus) before it would appear of its own accord. 18

The word abortion referred to in this study is applied to the "dispossessing from the womb, an occupant which is not fully formed and cannot and does not live after expulsion."19 According to the Joint Program for the Study of Abortion (JPSA) in 1971, one of the safest ways to terminate a pregnancy is by therapeutic abortion during the first seven to eight weeks of gestation. 20 The two methods now most used by American doctors during the first twelve weeks (first trimester) are the "D and $C$ " (dilation and curettage), which involves scraping the womb with a curette; and the second is "aspiration," or suction curettage technique. Between sixteen and twenty-two weeks, pregnancy is terminated by saline abortion, which involves a saline injection into the womb to induce labor. 21,22

"Until the late 1960 's, abortion was the only medical procedure regulated by criminal law." 23 By the passage of Colorado's abortion law in April 1967, abortion became a legal right of choice for women. 24 By June 1970, four states had virtually repealed all statutes regulating termination of pregnancy, seventeen states had reformed their abortion laws, and only four states did not have repeal or reform bills before their legislation. 25 
In January 1973, the U. S. Supreme Court announced its decision that state laws may not interfere with the right of a woman to have an abortion in the first three months of pregnancy (first trimester). During the second trimester, when abortion is more hazardous, the state's interest in the health of the woman permits the enactment of regulations to protect maternal health, such as statutes specifying where abortions may or may not be performed. After the fetus has reached the stage of viability, corresponding to approximately the last three months of pregnancy, the state can exercise an interest in promoting potential human life. It may do so by prohibiting abortions except when it is necessary to preserve the life or health of the mother. The Court's decision rendered all original and reform laws unconstitutional. 26

In 1971, the President of the United States expressed his views publicly on abortion: "From personal and religious beliefs, I consider abortion an unacceptable form of population contro1."27 The President's public declaration propelled the abortion issue into the political arena of the 1972 elections. ${ }^{28}$ The bringing of the abortion issue into the political arena gave rise to the open expression of the moral and ethical issues that have been inherent in the abortion controversy as far back as history acknowledges the existence of abortion. ${ }^{29} \mathrm{Mr}$. Justice Blackmun took these issues into account in writing for the majority of the Court 
in the Roe $v$. Wade decision (one of two cases that established the legalization of abortion in January 1973).

One's philosophy, one's experiences, one's attitudes toward life and family and their values, and the moral standards one establishes and seeks to observe are all likely to influence and to color one's thinking and conclusions about abortion. 30

Since abortion involves the issues of a person's own intrinsic value system as well as the practical issue of family size once an unwanted pregnancy occurs, numerous studies were conducted to ascertain what, if any, emotiona1psychological ill effects are manifest in women due to their having had an abortion. The majority of these studies were conducted before abortion was nationally legalized, and even then, when women who sought abortion by illegal means were studied, it was found that abortion caused a stress no more severe than other non-specific factors: disappointment in love, an accident, or loss of a job. 31

In studies conducted since the Supreme Court decision of 1973, one would expect women to suffer less from the experience, presumably because it is much easier now to qualify for an abortion. Studies in California, Colorado, and New York indicate this is true. "Today, patients generally have a positive reaction to the procedure, and experience little, if any, guilt after the operation." 32

From the numerous studies conducted to ascertain and define emotional stress due to having had an abortion and the concurring conclusions that such stress is minimal, in 
fact less than hypothesized, the researchers conclude that abortion studies tend to be needed in areas of abortion service availability, or non-availability, and the factors that lead into access of abortion services, i.e., education, and information available through media and community resources, the number of clinics that provide services in ratio of population, and the cost of obtaining abortion procedures and accessibility of funding particularly for low income women.

\section{PART II}

In 1975 , there were over 10,000 abortions performed in Oregon. The total number of pregnancies for that year increased by 3,000 over the previous year. Of these 3,000, 2,000 ended in abortion. 33 of these abortions, two-thirds were performed on women eighteen years and older. ${ }^{3}$ Nationwide abortion is on the increase. In 1969, the legal abortion ratio was 6.3 abortions per 1,000 live births. By 1973, the year of the U. S. Supreme Court decision to legalize abortion, the ratio had increased to 195.1 , nearly 20 percent of the frequency of live births. 35 In 1975 , approximately one million women in the United States obtained legal abortions. 36

Neither government support for abortion services nor the availability of private services have kept pace with the demand for abortion that has followed its legal sanction. 37 
Numerous women will seek to terminate an unwanted pregnancy by abortion whether it is legal or not. In 1974, one year after the Supreme Court abortion rights decision, 30 to 50 percent of all American women in need of abortion services were unable to obtain them, according to a nationwide survey conducted by the Alan Guttmacher Institute, the research and development area of the Planned Parenthood Federation of America. ${ }^{38}$ The problems of providing the public with accurate information, which can be the basis for appropriate attitudes and informed individual decisions about the use of abortion as a means of birth prevention, are more difficult to solve than straightforward technical problems. ${ }^{39}$ In reviewing the available 1iterature, research has not been directed to the issue of just how accessible and advertised information on abortion is, i.e., facilities, procedures, counseling services, and referral sources. In June 1975, the U. S. Supreme Court further increased the accessibility of information on abortion by ruling that the First Amendment of the Constitution, which protects freedom of the press, cannot restrict the advertisement of abortion services. 40

Access to health services performing abortions involves, principally, problems in the provision of medical care--availability of appropriate facilities and properly trained personnel, methods of financing, and organization of services. Modern abortion laws are of little avail 
without these provisions. ${ }^{41}$ According to D. Spalding,

The [lack of] availability of abortion services is a grave problem in many areas of the country. Hospitals aren't always willing to provide abortion services and almost always charge more than clinics. Although clinics have developed and continue to spread, there simply aren' $t$ enough of them to go around and women often have to travel to neighboring states to secure abortions. 42

According to one study, three-fourths of women who need abortions in the United States live in the 250 metropolitan areas, and half of them live in only ten states. The availability of services is also geographically concentrated. The study showed New York and California as reporting half of all nationwide abortions in 1973. No abortions, or very few, were reported in Louisiana, Mississippi, North Dakota, Utah, and West Virginia. At least one-fifth of women who had abortions in 1973 were forced to travel to other states for this service. 43

Of those women who obtained abortions in 1974, 67 percent were white and 29 percent were black. The racespecific ratios per 1,000 live births were as follows: white, 270 abortions; blacks, 421 abortions. Seventy-one percent of abortion-seekers were single, widowed, separated, or divorced. 44 In Freeman's article, she examines the accessibility to abortion by poor women. She stated that Title XIX (the Medicaid section) of the Social Security Act, which provides funds for medically necessary treatment for the indigent, is the main source of public funding for abotion since the Department of Health, Education and 
Welfare (HEW) has excluded abortion procedures from its funds for family planning. Frequently, the term "medically necessary treatment" is interpreted to restrict compensation to the therapeutic abortion that was previously allowed to save the life of the mother or to prevent the birth of a deformed child. Thus, abortion on request is effectively denied to many who depend on Medicaid payments. ${ }^{45}$ Medicaid payments have been limited to in-hospital services, despite the fact that the majority of early legal abortions are performed in reliable outpatient clinics. According to Freeman, this is contradictory to the development of abortion services that are simple and cost effective and that can be performed on an outpatient basis. ${ }^{46}$ In July 1975, under the "equal access" clause, the U. S. Third Court of Appeals ruled that the state of Pennsylvania was obliged to defray the cost of abortions for poor women without regard to "medical necessity." 47 The Social Security Administration has identified 5.3 million medically indigent women of childbearing age and of these, 14 percent, at most, are estimated to be eligible for Medicaid. ${ }^{48}$ This indicates that the 4.6 million poor women who are eligible for Medicaid have a proportionately greater problem in being granted services than the welfare population itself. ${ }^{49}$

As of June 1976, Medicaid paid for an estimated 250,000 to 300,000 abortions for the poor and near-poor, at a cost of $\$ 45$ million to $\$ 55$ million a year. ${ }^{50}$ HEW 
estimated that if Medicaid payments for abortions were withdrawn, with the exception of women whose health or welfare is in danger, it would cost federal, state, and local governments close to $\$ 500$ million in publicly assisted maternal and pediatric care and welfare. 51

It would seem that a misconception persists that the poor are not interested in abortion and that, in contrast, fertility is desired. 52 Data indicate that illegal abortions, often crude and self-induced, continue to be attempted by women who are unable to pay for legal abortions. 53 Studies have tied the rate of illegal abortions among the poor to the availability of legal abortion services. In one study, the number of emergency room complications from illegal abortions remained constant from 1969 to 1972 , the year in which a sharp decline began. This decline became apparent only when the hospital's rate of legal abortions reached 277 abortions per 1,000 live births. ${ }^{54}$ According to Freeman, the decline is believed to demonstrate the necessity for broad availability of services in order to reduce the desperate attempts at self-induced abortions among poor women. 55

According to John H. Knowles, M.D., president of the Rockefeller Foundation,

I believe we know enough about how the free market operates in medical care generally to assess that prompt action is absolutely essential. The free market has not provided accessible services to the poor . . . and it has placed too much emphasis on the ability to pay as 
contrasted with need as the prime determinant for the receipt of [abortion] services. 56

From the literature reviewed, the researchers conclude that there is at the present time, a lag between the abortion services available and attainable and the enactment of the U. S. Supreme Court decision enabling women to seek and procure a legal abortion.

According to the literature reviewed, the main sources of sex education, including contraceptive knowledge, are the family, friends or peer group, and the school.

Some articles concerning sex education have found that students first learn about sex education from the family. However, studies have shown that parents never really get around to meaningful discussion of sex with their children whether they are well-educated or not. 57

When the family fails in sex education, the second source of knowledge becomes the peer group. In Delores MaloJuvera's discussion of pregnant teenagers' knowledge of sex, she states that because sex is a peer approval activity, sex education is a peer phenomenon. 58 The third source of sex education for the adolescent and pre-adolescent is the school sex education program. These school programs, however, vary widely as to the amount of and explicitness of contraceptive methods as a part of the sex education experience.

In the findings of the study done by Carter et al. of teenage girls seeking abortion at the Oregon Medical School, the single most significant finding concerned the girls' 
knowledge of contraceptive devices and the utilization of these methods. The findings showed that all of the girls studied had some awareness of the functions or existence of various birth control methods that are medically considered most effective,

The fact that these girls requested abortions indicates that they did not want to become pregnant. Therefore, the reasons they did not use the most effective birth control methods or not take any precautions at all, have to be more complex than just being aware of birth control. That is to say, emotional, social, and environmental factors seem very much a part of their decision to use birth control.

Carter goes on to conclude,

It points directly to the failure of the methods or techniques employed to educate these girls in the area of birth control and sex education. This applies particularly to the schools since they were primary sources of birth control information. The approach used in this education process does not seem to free the person being educated to utilize the knowledge given. Evidently, sheer facutal data is not effective in preventing unwanted pregnancies. A more personal, open, and confidential way of giving and receiving contraceptive information is necessary. 59

We, the researchers, agree with Carter's conclusion; namely, that a more personal, open, and confidential approach to the exchange of contraceptive information could well be applied to the giving and receiving of abortion information. Through the education of parents of adolescents and pre-adolescents, through community resources such as Planned Parenthood, and by the education system taking a more human approach to the information-giving process, fewer unwanted pregnancies are likely to occur. 


\section{METHODOLOGY}

Recognizing the necessity for more extensive information and exploration concerning the pragmatic needs facing women who are seeking abortion, it was decided that a needs assessment survey might provide the desired information. Having made this decision, it became apparent to the researchers that the following steps needed to be undertaken and completed: (1) choice of an agency, (2) choice of a respondent population, (3) instrument development and design, and (4) instrument administration. Each of these four areas will be discussed in the following section.

\section{CHOICE OF AN AGENCY}

Upon consideration of several abortion resources in the Portland area, Lovejoy Specialty Hospital became the number one choice of the researchers. This choice was made for several reasons: (1) previously, one of the researchers had been a counselor at the clinic and was familiar with staff, procedures, and information regarding the agency; (2) Lovejoy Specialty Hospital is an agency which provides thorough services before, during, and after the abortion; and (3) a two-week follow-up examination is part of the 
hospital procedure and this would provide the researchers with a convenient time frame in which to collect the data. In early May, a phone call was made to Alene Klass, chief hospital administrator. A brief explanation was given of the research topic and an appointment was scheduled for a meeting. At this time the needs assessment idea was discussed in depth and Mrs. Klass gave her approval and support. It was decided that upon completion of the survey instrument, the researchers would return for instrument approval and recommendations.

\section{DESCRIPTION OF LOVEJOY \\ SPECIALTY HOSPITAL}

Lovejoy Specialty Hospital is a unique facility 1ocated at 933 N.W. 25th Avenue, Portland, Oregon. It is the only hospital in the state licensed by the State Board of Health to terminate pregnancy. All women are eligible for services provided they are willing to work with a counselor and provided they are willing to decide on a mutually agreeable payment plan. The agency is set up as an outpatient facility where therapeutic abortions are performed on a oneday basis. All patients are counseled prior to treatment where pregnancy alternatives (adoption, abortion, single parenthood) are carefully discussed and explored. If an abortion is chosen, a day is appointed and at that time the procedure is performed. Counselors are with the patient 
throughout the day of the procedure to talk about feelings and operation procedures. The hospital works with these women and their families on a follow-up basis individually designed for each woman. At this time several issues may be discussed, such as: after-effects of termination, and information on birth control and contraceptive methods of the woman's choice. Contraceptive devices are supplied. Most of this is done at the routine two-week follow-up medical exam provided for each woman. In addition, Lovejoy Specialty Hospital provides a host of other services such as: vasectomy counseling and procedure, pap smear administration, and a complete referral system to outside agencies.

\section{CHOICE OF RESPONDENT POPULATION}

The respondents to be used in this study included all those women returning for their two-week follow-up examination at the hospital. This population varies greatly in its demographic characteristics, which will be explored more fully in the data analysis. This group does not represent the total population of abortion patients at the hospital, since many women chose not to return for a follow-up examination. Although this could present certain biases in our sample, it was still felt that assessing this group of women would be a beginning toward providing information in this area. 


\section{INSTRUMENT DEVELOPMENT AND DESIGN}

After sanction was received from the agency, the researchers began to develop the research instrument. It was decided that a survey questionnaire would be the primary means of gathering information. This was to be followed by several in-depth personal interviews to be used to supplement or clarify the data obtained from the questionnaires. Additionally, the interviews could be used as a means to obtain new information which was not received through the questionnaire.

The format of the questionnaire is divided into three sections: (1) the cover letter, (2) demographic information, and (3) the main body of the questionnaire. The purpose of the cover page was to explain who the researchers were and to describe the intentions of the research project, to thank the respondents for their cooperation, to insure the respondents of complete confidentiality, and to inform them that the results of the research could be obtained at the Portland State University School of Social Work in the Spring of 1977.

The main body of the questionnaire focused on three major areas: (1) availability of information concerning abortion and access to abortion services within the community, (2) availability of information concerning birth control and access to birth control resources within the 
community, and (3) affordability of abortion services within the community.

After the construction of the first draft of the questionnaire, the researchers returned to Lovejoy Specia1ty Hospital, as requested. The researchers met with Mrs. Klass and an abortion counselor. A review of the instrument was made, at which time several questions were added, others clarified, and wording revised. The final questionnaire was approved at this time.

\section{PRETEST}

The questionnaire was pretested by eight follow-up patients in July 1976. This was done in the interest of refining the instrument and assessing the instrument's clarity. Through this process, two questions were modified: question 11 are reworded for clarification purposes, and question 13 was revised by adding "Why?"

\section{INSTRUMENT ADMINISTRATION}

The questionnaire was administered by two of the researchers, one day a week, over an eight-week period. This was done in August and September of 1976. These days were chosen through the use of a random numbers table in order to reduce the chance of bias occurring in the choice of days. Every woman returning for a two-week medical follow-up examination on the day chosen was given the questionnaire 
with a minimum of explanation. They were told to read the cover letter which would explain the intentions of the researchers. No woman refused to complete the questionnaire. By the end of September, sixty-six questionnaires were completed.

In December 1976, five personal interviews were conducted. The researchers interviewed young teenage women and women in their late thirties. Both of these age groups had been somewhat absent within our questionnaire population. The data was supplemented through these personal interviews. The information obtained in the personal interviews was used primarily as anecdotal information in the research findings and conclusions sections of the study. After the personal interviews were conducted, the data collection was complete. 


\section{FINDINGS}

The primary aim of the findings section is to provide a clear, factual description of the data collected from the questionnaire (see Appendix I). The researchers have chosen to comment on specific data that represent the findings of interest, most commonly those of the highest and lowest percentiles, and have chosen to exclude other data that falls in between these two categories in order to keep the findings concise. The following tables represent data collected from the sixty-five respondents to the questionnaire.

\section{TABLE I}

AGE OF RESPONDENTS

\begin{tabular}{crr}
\hline \hline Age & $\mathrm{f}$ & $\%$ \\
\hline 15 and under & 3 & $5 \%$ \\
$16-20$ & 31 & $48 \%$ \\
$21-25$ & 19 & $29 \%$ \\
$26-30$ & 8 & $12 \%$ \\
$31-35$ & 1 & $2 \%$ \\
$36-40$ & 2 & $3 \%$ \\
41 and over & 1 & $1 \%$ \\
Total & 65 & $100 \%$ \\
\hline \hline
\end{tabular}

It was interesting to note that almost all of the women out of a total of sixty-five respondents ( 89 percent) were between the ages of fifteen and thirty. The mean age is 21.59 years. The age range is thirteen to forty-three 
years. On1y one respondent, forty-three years of age, was in the "forty-one and over" category.

TABLE II

OCCUPATION OF RESPONDENTS

\begin{tabular}{lrr}
\hline \multicolumn{1}{c}{ Occupation } & $\mathrm{f}$ & \multicolumn{1}{c}{$\%$} \\
\hline Homeworker & 7 & $11 \%$ \\
Salesworker & 4 & $6 \%$ \\
Officeworker & 14 & $21 \%$ \\
Social Service & 2 & $3 \%$ \\
$\quad$ Worker & 7 & $11 \%$ \\
Restaurant Worker & 12 & $18 \%$ \\
Student & 5 & $8 \%$ \\
Other & 5 & $8 \%$ \\
Unemployed & 6 & $9 \%$ \\
No occupation & 3 & $5 \%$ \\
No answer & 65 & $100 \%$ \\
$\quad$ Total & & \\
\hline \hline
\end{tabular}

The categories reflected in Table II are a generalization of a variety of occupations similar enough to warrant the same classification. For example, out of the total of four salesworkers, one is a checker, two are sales clerks, and one is a life insurance underwriter. Another example of this classification system is the "Officeworker" category. Included are one assistant to an accounting controller, one bookkeeper, one legal assistant, one bank administrator assistant, six secretaries, one receptionist, one office manager, and two file clerks. The "Other" category reflects those occupations which cannot be appropriately included in any of the other classifications. They include one photographer, two factory workers, one tree planter, 
and one chemist. Of the total of sixty-five respondents, five indicated that they are unemployed, six gave no occupation, and three answered with a "No response."

\section{TABLE III}

EDUCATIONAL BACKGROUND OF RESPONDENTS

\begin{tabular}{lrc}
\hline $\begin{array}{l}\text { Educational } \\
\text { Background }\end{array}$ & $\mathrm{f}$ & $\%$ \\
\hline $8-11$ & 16 & $23 \%$ \\
12 of high school & 20 & $30 \%$ \\
Business or trade & 8 & $12 \%$ \\
school & 14 & $21 \%$ \\
Four year college & 3 & $5 \%$ \\
Graduate school & 6 & $9 \%$ \\
Some college* & 65 & $100 \%$ \\
$\quad$ Total & & 9 \\
\hline
\end{tabular}

*Originally this category was "Other." Since all of the responses in the "Other" category indicated some college, the category was changed to "Some college" in Table III.

When the respondents were asked to check the space which most clearly described their educational background, twelve had completed or were still in the "8-11" grade category, twenty had completed the twelfth grade or high school, eight had completed business or trade school, thirteen had completed a four-year college, three had completed graduate school, and four had completed some college.

The participants were then asked whether or not they planned to attend school in the coming year; thirty-five replied "Yes," twenty-nine replied "No," and one respondent was unsure. 


\section{TABLE IV}

LIVING ARRANGEMENTS WHEN RESPONDENT

LEARNED OF PREGNANCY

\begin{tabular}{lrc}
\hline \hline \multicolumn{1}{c}{ Living } & & \\
Arrangements & $\mathrm{f}$ & $\%$ \\
\hline Living alone & 13 & $20 \%$ \\
Living with parents & 24 & $37 \%$ \\
Living with friends & 9 & $14 \%$ \\
Living with mate & 18 & $28 \%$ \\
Other* & 1 & $1 \%$ \\
$\quad$ Total & 65 & $100 \%$ \\
\hline
\end{tabular}

*Living with aunt.

As Table IV shows, out of sixty-five women, 37 percent, or most of the women, were living with their parents, while 28 percent were living with their mate, and 14 percent were living with friends.

\section{TABLE V}

NUMBER OF CHILDREN

\begin{tabular}{crc}
\hline \hline Children & f & $\%$ \\
\hline Yes & 18 & $28 \%$ \\
No & 47 & $72 \%$ \\
Total & 65 & $100 \%$ \\
\hline
\end{tabular}

It was interesting to note that 72 percent of the total of sixty-five women indicated that they did not have children, while 28 percent did have children.

of the eighteen women who indicated they did have children, eleven women had one child, the average age being 
two and one-half years; four women had two children, the average age for the oldest being 13.1 and the youngest being 9.7; and two women had three children, the average age for the oldest being eight, the middle child being 5.3 , and the youngest being 10.5 months.

In regard to whether or not the women had someone to confide in when they learned of their pregnancy, sixty-three out of sixty-five women stated that they did have someone in whom to confide, two stated that they did not. The researchers were unable to determine whether or not the respondents were referring to the counselors at Lovejoy Specialty Hospital as their confidants or if they were referring to individuals outside the hospital setting.

\section{TABLE VI}

FEELINGS AFTER THE ABORTION

\begin{tabular}{lc}
\hline \multicolumn{1}{c}{ Feelings } & $\mathrm{f}$ \\
\hline Comfortable with decision & 42 \\
Want to forget about abortion & 21 \\
Know more about yourself as & 21 \\
a person & 3 \\
Feel it was a negative ex- & 0 \\
perience & 2 \\
None of the above & 1 \\
Other & $90 \%$ \\
No answer & $90 \%$ \\
$\quad$ Total
\end{tabular}

*Equals more than sixty-five since respondents could answer more than one time. 
It is interesting to note that forty-two women, which is more than two-thirds of the respondents, reported that they felt comfortable with their decision to have an abortion. Only three women felt that having an abortion was a negative experience. Of the two responses in the "Other" category one woman wrote, "I regret the loss of a child I might have wanted." The other respondent stated, "I am sorry I got myself into this position but now I have to live with it." Out of the women who gave multiple answers, eleven women felt comfortable with their decision to have an abortion. Four women who gave multiple responses reported that they were both comfortable with their decision to have the abortion and that they want to forget about the abortion.

TABLE VII

SERVICES RESPONDENTS WOULD USE IF PROVIDED

\begin{tabular}{lr}
\hline \multicolumn{1}{c}{ Services } & $\mathrm{f}$ \\
\hline Abortion Hot Line & 15 \\
Contact with other women & 24 \\
Rap groups & 8 \\
Pregnancy Counselor & 33 \\
None of the above & 9 \\
Other & 0 \\
No answer & 5 \\
Total & $94 \%$ \\
\hline
\end{tabular}

$*_{n}=$ more than sixty-five because respondents could respond in one category or more. 
The categories which received the most responses in Table. VII were "Contact with other womęn" and "Pregnancy Counselor." Over one-half of the women stated that they would use a pregnancy counselor if such services were available, and one-third (twenty-four out of sixty-five) would choose contact with other women going through an abortion. Out of sixth-five respondents, no one answered in the "Other" category, and nine women indicated "None of the above."

The respondents were asked if they had knowledge about birth control methods prior to their pregnancy. The data shows that out of a total of sixty-five women in the study, sixty-two of them stated that they did have birth control information, two women indicated that they did not, and one woman did not answer.

\section{TABLE VIII}

SOURCE OF BIRTH CONTROL INFORMATION

\begin{tabular}{lr}
\hline \multicolumn{1}{c}{ Source } & f \\
\hline Friends & 9 \\
Family Doctor & 22 \\
Planned Parenthood/other & 24 \\
$\quad$ family planning agencies & 5 \\
Family & 7 \\
School & 4 \\
Media & 3 \\
Other & 5 \\
No answer & $79 *$ \\
$\quad$ Total & 79 \\
\hline
\end{tabular}

$*_{n}=$ more than sixty-five since respondents answered more than once even though the questionnaire asked for only one main source. 
The categories which received the most responses were those of "Family Doctor" and "Planned Parenthood." Out of the sixty-five women, twenty-two stated that they obtained birth control information from their family doctors, and twenty-four of the sixty-five women stated that they received their information from Planned Parenthood or other family planning agencies. Of the three respondents in the "Other" category, one woman stated that she studied about the subject extensively in graduate school. Another woman stated that she obtained the information through Washington County Health Clinic, and the third respondent indicated that she received birth control information through Lovejoy Specialty Hospital.

The women in the study were asked if they felt confident in their present knowledge concerning birth control methods. Out of the total of sixty-five respondents in the study, fifty-eight stated that they did feel confident, while six did not, and one woman did not answer.

Table IX shows that out of the total of sixty-five women, the highest number (fifty-four) indicated that they knew enough about abortion as an alternative to personally consider it. The fewest number of women (ten) indicated that they knew enough about adoption as an alternative to have personally considered it. 
TABLE IX

OPTIONS RESPONDENTS KNEW ENOUGH ABOUT TO PERSONALLY CONSIDER

\begin{tabular}{lc}
\hline \multicolumn{1}{c}{ Options } & $\mathrm{f}$ \\
\hline Abortion & 54 \\
Continue pregnancy/adoption & 10 \\
Continue pregnancy/single parenthood & 17 \\
Continue pregnancy/within present & 13 \\
family unit & 19 \\
Continue pregnancy/form family unit & 0 \\
with or without marriage & 1 \\
Other & $114 *$ \\
No answer & 1 \\
\hline
\end{tabular}

$*_{n}=$ more than sixty-five because respondents were told to answer in one or more categories.

\section{TABLE X}

SOURCE OF ABORTION INFORMATION PRIOR TO CONTACT WITH LOVEJOY SPECIALTY HOSPITAL

\begin{tabular}{lc}
\hline \hline \multicolumn{1}{c}{ Source } & $\mathrm{f}$ \\
\hline School & 13 \\
Family & 10 \\
Friends & 29 \\
Media & 15 \\
Family Doctor & 20 \\
Planned Parenthood/other family & 16 \\
planning agencies & 0 \\
Religious Organization & 3 \\
Other & $107 *$ \\
$\quad$ Total
\end{tabular}

$*_{n}=$ more than sixty-five because respondents could answer more than once.

The categories which received the most responses were "Friends" and "Family Doctor." Out of the total of 
sixty-five respondents, twenty-nine indicated that they received knowledge pertaining to abortions from friends, while twenty learned from their family doctors. Of the three responses in the "Other" category, one stated that abortion information was obtained through a doctor she listened to during a lecture, while the other two respondents stated that information was obtained through "selves."

In response to whether or not the respondents had difficulty obtaining information on abortions, three responded with "Yes," fifty-seven responded with "No," and five did not answer. Of the three who responded affirmatively, none of them specified the reasons why.

\section{TABLE XI}

SOURCES THROUGH WHICH RESPONDENTS HEARD ABOUT LOVEJOY SPECIALTY HOSPITAI

\begin{tabular}{lr}
\hline \multicolumn{1}{c}{ Source } & $f$ \\
\hline Representative from Lovejoy Specialty & 1 \\
$\quad$ Hospital & 20 \\
Planned Parenthood/other family planning & 25 \\
agencies & 24 \\
Family Doctor & 2 \\
Friends & 1 \\
School & 6 \\
Media & \\
Other & $83 *$ \\
$\quad$ Total & 83 \\
\hline
\end{tabular}

$*_{\mathrm{n}}=$ more than sixty-five due to multiple responses.

Out of a total of six responses in the "Other" category, three indicated information was obtained from the 
"Outside-In" clinic, one from a prior abortion, one from the Women's Health Clinic, and one from Clackamas County Health Clinic.

\section{TABLE XII}

DIFFICULTY EXPERIENCED BY RESPONDENTS

IN PAYING FOR ABORTION

\begin{tabular}{lrc}
\hline Response & $f$ & $\%$ \\
\hline Yes & 17 & $26 \%$ \\
No & 47 & $72 \%$ \\
No answer & 1 & $2 \%$ \\
Total & 65 & $100 \%$ \\
\hline
\end{tabular}

The highest percentage ( 72 percent) of the entire population in the study indicated that they did not have difficulty in paying for their abortion, while 26 percent did experience difficulty, the lowest percentage other than the 2 percent that did not answer.

The respondents who stated that they did have difficulty in financing the abortion were then asked to indicate how they handled it. Of the seventeen respondents who indicated difficulty in financing the abortion, five took money from their savings, eight borrowed the money from someone, one worked overtime, one used welfare, one used Project health insurance, and one did not specify.

Due to the inconsistency in the responses to the question concerning the respondents' difficultiy in paying for their abortion, the researchers were unable to analyze the 
results of the question. For example, forty-seven respondents indicated that they did not have difficulty in paying for their abortion, and fifteen responded to the question which asked "how they handled their difficulty in financing the abortion." 


\section{CONCLUSIONS AND IMPLICATIONS}

The research findings conclude that 94 percent of the sample of women in the study were under the age of thirty years. The majority of them fell between the ages of sixteen and twenty-five. It was found, also, that three women were between the ages of thirty-one and forty years, and one woman was forty-three years of age.

It would seem that many women between the ages of sixteen and twenty-five would be more inclined to terminate a pregnancy due to involvement in educational and career pursuits, and due to assessing their life goals and values. Another factor contributing to the relatively young ages of women obtaining abortions at Lovejoy Specialty Hospital is that women in their late thirties and forties tend to be past the prime age of childbearing. These women are more inclined to select other permanent forms of contraception such as tubal ligation, hysterectomy, or vasectomy. In addition, it is possible that women in this age group would tend to obtain abortions through their private physicians for two reasons: one may be that older women have more money to pay for an abortion in a hospital with a private doctor, and the other may be a greater desire for privacy and anonymity. 
The findings in the study concluded that fifty-one of the women (79 percent) were employed. The majority of the employed women (51 percent) were either students or employed in an office setting. In terms of educational background, the women, for the most part, were graduates from either high school or college, or had received a partial college education.

The researchers concluded that most of the women in the study ( 65 percent) were either living with their mate or with their parents. Two women who were personally interviewed, indicated that their mate, with whom they were living when they learned of their pregnancy, did have some influence upon their decision to have an abortion. The mates of both women had stated that they were not ready to have children in their relationships at this point in their lives.

Almost all of the women in the study (97 percent) said that they did have someone to whom they could confide when they learned of their pregnancy. Yet, from the data provided, the researchers cannot determine the kind of relationship the respondents had with the person to whom they confided. Nor can we specify how the respondents interpreted the term "confide."

It was concluded in the study that more than one-half of the women felt "comfortable" with their decision to have the abortion. It was found that only three women felt the 
abortion experience to be a "negative" one. The researchers cannot determine how the respondents interpreted either "comfortable" or "negative experience." For example, "negative experience" may refer to the medical procedure at the hospital, or to the emotional experience, or to the entire experience from the moment they learned of the pregnancy through the day of the procedure.

With this in mind, however, the researchers believe that the comprehensive services provided at Lovejoy Specialty Hospital had a profoundly positive influence upon the women's attitude toward their abortion decision and experience. These comprephensive services include complete abortion and pregnancy counseling, a supportive and medically safe atmosphere, and explicit information on the abortion procedure and birth control methods. There is another factor which may contribute to the relatively small number of women who felt their abortion experience at Lovejoy Specialty Hospital to be a negative one. Since the study was conducted two weeks after the abortion, many women may have forgotten about the negative aspects of the experience. In other words, the two-week interval may have served to desensitize feelings and attitudes regarding the abortion. The researchers have no way of knowing how those women who did not return for a two-week follow-up felt about their abortion experience. Perhaps these women may have felt more negative than the population that was studied. 
It was found in the study, that if provided, almost all of the women would use services such as rap groups, an abortion hot line, contact with other women obtaining an abortion, and pregnancy counselors. More specifically, the study found that women between the ages of sixteen and twenty would utilize services which provide contact with other women who have gone through an abortion, as well as services which provide contact with pregnancy counselors.

It was the intention of the researchers to discern, from the respondents, what services they would use other than those provided at Lovejoy Specialty Hospital. Since we did not make that clear, we have no way of knowing whether or not those who indicated pregnancy counselors were speaking of the counselors at Lovejoy, or a different type of counselor, within a different setting. Despite this confusion, comments obtained through the personal interviews further substantiated the conclusion that there is a need for additional abortion services. One woman commented,

During the first critical days after I found out that I was pregnant, I tried to find any information about alternatives to abortion, but it appeared as if no one could supply me with the information.

Another woman said, "Other services would be helpful because friends may not want to hear about it." A third woman stated,

I would want contact with other women in a similar situation because it would help me understand what I went through psychologically. It would be supportive to hear from others who are in the same place. 
It was interesting to note that women who had someone in whom they confided, also would use alternative abortion services in the community. Services they would utilize include an abortion hot line, pregnancy counselors, and contact with other women having similar experiences. In addition, women who indicated they felt comfortable with their decision to have the abortion, wanted to forget about the experience, and knew more about themselves after the abortion experience. All indicated they would use the alternative services mentioned above.

These conclusions were interpreted by the researchers to mean that although the women in the study were apparently able to meet most of their needs, they still have other needs which are unmet. For example, perhaps the persons to whom the women confided were able to provide support, acceptance, and help in decision making, but did not provide the necessary information which an abortion hot line could deliver. It may also follow that the women who stated that they wanted to forget about the abortion experience, need to do that with other women who have gone through a similar experience.

It appears from these conclusions that women do in fact need programs and services provided, in order to meet their needs when obtaining an abortion. Community resources such as public schools, health departments, women's clinics, mental health settings, and public welfare 
departments should be examined for their potential accessibility in providing both information and services for those women who are not reached by Lovejoy Specialty Hospital.

One of the major areas of study undertaken was for the purpose of finding out whether or not birth control information and dispension of methods are available to all women. Almost all of the respondents in the study did have birth control information available to them prior to their pregnancy. The two most often mentioned informational sources were Planned Parenthood and family doctors. It was also concluded that the majority of women ( 89 percent) felt confident with their present knowledge of birth control methods .

The conclusion from the study would suggest that women do not need additional services for birth control information and dispension of methods. However, the fact that these women were terminating a pregnancy indicates a possible discrepancy between knowledge and possession of birth control devices and their utilization.

Although many women in the study either currently attend or have attended school in the past, few indicated that they received birth control information from schools. Yet, since the majority of the women in the sample population were of school age, the researchers contend that programs providing both birth control information and dispension of methods should be incorporated into public and 
private school systems. The implication is that early, thorough, and factually-based education concerning birth control might alleviate the discrepancy that appears among women who are terminating an unwanted pregnancy but also indicate knowledge of birth control measures.

A second major area of study undertaken was to determine if the previous literature and research pertaining to women and abortion tends to emphasize the psychological and emotional ramifications. It was found that many of the studies and articles do focus upon the mental and emotional effects of abortion upon women. The research which tends to emphasize these effects was done, predominately, prior to the Supreme Court's decision to legalize abortion in 1972. The reasons for this tendency may be speculated upon in the following way: prior to 1972, abortions were a criminal offense in many states throughout the country. The decision to have an abortion involved some profound value conflicts. If a woman were to choose to have an abortion, her personal feelings, values, and attitudes would be in direct conflict with those social and legal norms opposing the issue of abortion. Thus evolved the notion that a woman would most definitely suffer emotional and psychological effects as a result of these value conflicts. It would stand to reason that after the legalization of abortion in 1972, that more articles and studies would be done which emphasized the sociological and pragmatic aspects pertaining 
to the issue of abortion. For as the law began to be implemented throughout the country, studies were needed to determine if the law was being executed effectively.

The third major focus of this study dealt with whether or not women have, when faced with an unwanted pregancy, the necessary current information regarding procedures, facilities, and pragmatic details. It was concluded from this study that nearly all of the respondents did have access to information regarding abortions and related services. The most frequently mentioned source of abortion information was friends and family doctors. Specifically, women learned about Lovejoy Specialty Hospital most frequently through Planned Parenthood, friends, and family doctors. Although the findings conclude that 97 percent of all the respondents in the study did not experience difficulty in obtaining this information, their indication of a desire for an abortion hot line may point to a need to have additional information and different types of services.

It is important to note that the issues affecting the women in this study could, potentially, have an effect upon all women at some point in their lives.

It was found in the study that nearly one-third of the respondents did have difficulty paying for their abortions. Most of these women handled this difficulty by borrowing the money or by taking it from their savings. However, the researchers are unable to assess how the 
respondents interpreted the issue of "financial difficulty." For example, some women indicated that taking money from savings did make their abortion difficult to finance. Other respondents who took money from their savings did not experience difficulty in financing their abortion. One woman stated in a personal interview,

I did have difficulty paying for my abortion. Obtaining welfare was a "horrible and humiliating experience." I had to stand at an open counter and explain why I needed the special grant. I had to tell a young man three times that it was not for child support, but rather for an abortion. They wanted the father's name. I refused to give it to them and therefore had to sign an "absent parent" form to the effect that the father was unknown. Women who have to use welfare for an abortion need support from women who care, not a man who apparently was making some sort of a moral judgement.

Based on these findings, it can be seen that financial pressures do exist for some women who seek abortions. The researchers strongly contend that programs and services need to be developed for the purpose of providing financial assistance to women who are unable to finance their abortions. Since Medicaid (welfare) payments cover all other medical expenses for women, they should also cover abortion costs. Based upon one woman's experience with the Welfare Department, mentioned above, it is believed that service providers within the Welfare Department, as well as other community agencies, should be trained to be supportive and effective in working with women going through the experience of having an abortion. 
In summary, the study indicates that most women were able to obtain birth control and abortion information, had access to services and facilities in the community, and, for the most part, did not have difficulty paying for their abortions. However, the literature review suggests that many women still experience grave problems in obtaining abortion information and services in many communities throughout this country. Abortion on request is effectiveIy denied to many women who depend upon Medicaid (welfare) payments. Therefore, the researchers believe that we must continue to strive to provide all women with feasible, accessible, and extensive abortion services. 


\section{RECOMMENDATIONS}

In undertaking this research, several other areas in need of further investigation became apparent.

The researchers recommend that one such area of study would be to ascertain from non-pregnant women of varied socioeconomic backgrounds and age groups, the needs surrounding information on abortion and birth control. By assessing these needs, perhaps more preventative programs can start being incorporated against unwanted pregnancies.

Second, a study could be undertaken to assess the needs of more specific populations of women in need of an abortion. We, the researchers feel that the reason the results came out as they did, indicating that basically the population studied had their abortion needs met, was due to the population being skewed. The researched population was homogeneous in that they all used the same facility. A follow-up study should include not only Lovejoy Specialty Hospital, but other facilities that perform abortions such as the County Hospital and perhaps private physicians. There are two populations, in particular, which the researchers feel require more intensive investigation. They are teenage women and women on welfare. The literature reviewed indicated an increasing number of teenage 
preganancies. Due to their age, the researchers feel that this group of women might encounter special problems and have unique needs. The literature also indicates that women on welfare are reportedly having difficulty financing abortions. Both of these groups require more research directed toward assessing their needs.

Third, the researchers realize that since this study was done at a two-week follow-up examination after the abortion, many women might tend to deemphasize the needs they had before or immediately after the abortion. For this reason, a third area of study might be to determine the needs of these women at various time intervals prior to their abortion, immediately after their abortion, and a follow-up study done six months after the abortion. In this way, needs can be ascertained at a variety of time intervals surrounding the abortion.

Fourth, the researchers feel that a larger number of personal interviews might have increased the accuracy and specificity of the information received. Due to the nature of closed-ended questions, in that they force the respondent to choose among already fixed answers, and that they do not allow for qualifications to an answer, the amount of information obtained from our respondents was limited. Personal interviews allow the respondent more freedom to answer a question in the manner he/she chooses, which allows for more 
spontaneous and value-laden aspects of the respondent's answer.

Whatever future research is done surrounding abortion, it is paramount not to assume that simply because legislation has legalized abortion, that services are meeting all the needs of these women. It is essential that we all continue to strive to improve the quality of these services in order to insure equal access to all women. 


\section{LIST OF FOOTNOTED REFERENCES}

${ }^{1}$ Ibtihag Arafat and Ruby M. Chireau, "The Psychological and Emotional Affects of Abortion" (Research Report, City College of the City University of New York, 1973).

2 R. M. Boyce and R. W. Osborn, "Therapeutic Abortion in a Canadian City," The Canadian Medical Association Journal 103 (Sept. 1970): 461-5.

$3^{3}$. Ekblad, "Induced Abortion on Psychiatric Grounds," Acta Psychiatrica Scandinavica (1955), Supplement 99.

${ }^{4}$ Howard Levine and Francis Pugney, "Law, Preventative Psychiatry and the Therapeutic Abortion," The Journal of Nervous and Mental Disease 151:51-7.

5 Jerome M. Kummer, "Post Abortion Psychiatric Illness --A Myth?" The American Journal of Psychiatry 119 (April 1963): $980-3$.

${ }^{6}$ Nathan Simon et al., "Psychiatric I1lness Following Therapeutic Abortion," The American Journal of Psychiatry 124 (July 1967): 59 .

${ }^{7}$ G. G. Walter, "Psychological and Emotional Consequences of Elective Abortion: A Review," Obstetrics and Gynecology 36 (September 1970):482-91.

${ }^{8}$ William M. Nathe and Ike R. Lacefield, "Degree of Depression in Women Preceding Abortion at the University of Oregon Medical School," Graduate School of Social Work, Portland State University Graduate School of Social Work, 23 February 1972 .

${ }^{9}$ M. S. Calderone, ed., Abortion in the United States (New York: Hoeber Harper, 1958).

${ }^{10} \mathrm{P} . \mathrm{H}$. Gehbard et al., Pregnancy, Birth and Abortion in the United States (New York: Harper and Row, Inc., 1958).

${ }^{11}$ Colleen P. Harrison, "Teenage Pregnancy--Is Abortion the Answer?" The Pediatric Clinics of North America, vol. 16, pp. 363-9. 
${ }^{12} \mathrm{~T}$. Ledz and H. Rozen, eds., Therapeutic Abortion (New York: Julian Press, 1954).

${ }^{13} \mathrm{R}$. Roemer, "Abortion Law Reform and Repeal: Legislative and Judicial Developments," American Journal of Pub1ic Health 61 (March 1971):500.

${ }^{14}$ Edmond W. Overstreet, "California's Abortion Law-A Second Look," in Abortion and the Unwanted Child, ed. Car1 Reiterman (Springer Publishing Co., Inc., 1971), pp. 19-20.

${ }^{15}$ New York City Abortion Report: The First Two Years, October 1972, pp. 1-2.

${ }^{16}$ Atlanta, Georgia Center for Disease Contro1, Abortion Surveillance, 1974.

${ }^{17} \mathrm{C}$. Tietze, "Mortality with Contraception and Induced Abortion," in A Study of Family Planning, vol. 45 (1969), pp. 6-8.

$18 \mathrm{~J}$. Saltzman and Stanley Zimaring, Abortion Today (Springfield, I11.: Charles C. Thomas, 1973), p. 5.

${ }^{19}$ Ibid., p. 5.

${ }^{20} \mathrm{H}$. Osofsky and Joy D. Osofsky, The Abortion Experience (Hagerstown, N.Y.:- Harper and Row, 1973), p. 1.

${ }^{21}$ Saltzman and Zimaring, p. 9.

${ }^{22}$ C. Carter et al., "A Descriptive Study of Educational Background, Contraceptive Knowledge, and Choice of Agency Among Selected Girls 18 Years $01 d$ and Under Seeking an Abortion at the University of Oregon Medical School, "Portland State University School of Social Work, 1972.

${ }^{23}$ Alice S. Rossi, "Abortion Laws and Their Victims," Transaction (Sept.-Oct. 1966).

${ }^{24}$ Osofsky and Osofsky, p. 29.

${ }^{25}$ George Langmyhr and Walter Rodgers, Legal Abortion: A Guide for Women in the United States (New York, 1970), p.

${ }^{26}$ Saltzman and Zimaring, p. 69.

${ }^{27}$ New York Times, 4 April 1971, p. 33.

${ }^{28}$ New York Times, 7 May 1971, p. 29. 
${ }^{29}$ Nathe and Lacefield, p. 43.

${ }^{30}$ Osofsky and Osofsky, p. 281.

${ }^{31}$ Kummer, p. 982.

${ }^{32}$ M. Casaday, "Abortion: No Lasting Emotional Scars," Psychology Today 8 (November 1974): 148-9.

${ }^{33}$ Oregon State Health Department, "Induced Abortions," Oregon State Health Department, Vital Statistics, March 1976 .

${ }^{34}$ Ibid.

${ }^{35}$ Atlanta, Georgia Center for Disease Control, Abortion Surveillance, 1973.

${ }^{36}$ Edward Weinstock et al., "Abortion Need and Services in the United States, 1974-75," Family Planning Perspectives 8 (March/April 1976):58-9.

${ }^{37}$ Ellen W. Freeman, "Abortion: Beyond Rhetoric to Access," Social Work (November 1976): 483 . 225.

${ }^{38}$ Family Planning Perspectives 5 (Sept./Oct. 1975):

${ }^{39}$ Osofsky and Osofsky, p. 45.

40 Freeman, p. 483.

41 osofsky and Osofsky, p. 291.

42 Denise Spalding, "Abortions: Legal But How Available?" Ms., September 1975, pp. 103-6.

${ }^{43}$ Family Planning Perspectives, p. 225.

${ }^{44}$ Abortion Surveillance (1974).

${ }^{45}$ Ibid.

${ }^{46}$ Ibid.

${ }^{47}$ Freeman, p. 484.

${ }^{48}$ New York Times, p. 33.

${ }^{49}$ Ibid. 
50"Legislators Agree to Limit Abortion Under Medicaid," Los Angeles Times, Washington Post Pervice, 16 September 1976.

$51^{\text {Ibid. }}$.

52 Lee Rainwater and Karol $\mathrm{K}$. Weinstein, And the Poor Get Children (Chicago: Quadrangle Books, 1960).

${ }^{53}$ R. S. Kahan et al., "The Effect of Legalized Abortion on the Morbidity of Criminal Abortion," American Journal of Obstetrics and Gynecology 121 (January 1975):114-6.

${ }^{54}$ Ibid.

${ }^{55}$ Freeman, p. 484.

$56 \mathrm{~J}$. H. Knowles., "Public Policy on Abortion," Society 11 (July 1974): 15-8.

57 Nathe and Lacefield, p. 43.

${ }^{58}$ Delores Malo-Juvera, "What Pregnant Teenagers Know about Sex," Nursing Outlook 18 (November 1970):33.

${ }^{59}$ Carter et al., pp. 46-7. 
SELECTED BIBLIOGRAPHY

BOOKS

Atlanta, Georgia Center of Disease Control. Abortion Surveillance, 1973.

Abortion Surveillance, 1974.

Calderone, M. S., ed. Abortion in the United States. New York: Hoeber Harper, 1958.

Gehbard, P. H., et a1. Pregnancy, Birth and Abortion in the United States. New York: Harper and Row, Inc., 1958.

Langmyhr, George, and Rodgers, Walter. Legal Abortion: A Guide for Women in the United States. New York, 1970.

Ledz, T., and Rozen, H., eds. Therapeutic Abortion. New York: Julian Press.

New York City Abortion Report: The First Two Years. October 1972 .

Osofsky, H., and Osofsky, Joy D. The Abortion Experience. Hagerstown, N.Y.: Harper and Row, 1973.

Rainwater, Lee, and Weinstein, Karol K. And the Poor Get Children. Chicago: Quadrangle Books, 1960.

Saltzman, J., and Zimering, Stanley. Abortion Today. Springfield, Ill.: Charles C. Thomas, 1973.

\section{ARTICLES}

Arafat, Ibtihag, and Chireau, Ruby M. "The Psychological and Emotional Effects of Abortion." Research Report, City College of the City University of New York, 1973.

Boyce, R. M., and Osborn, R. W. "Therapeutic Abortion in a Canadian City." The Canadian Medical Association Journal 103 (September 1970). 
Carter, C.; Kirk, Lititia J.; and Ogier, Jan. "A Descriptive Study of Educational Background, Contraceptive Knowledge, and Choice of Agency Among Selected Girls 18 Years 01d and Under Seeking an Abortion at the University of Oregon Medical Schoo1." Portland State University School of Social Work, 1972.

Casaday, M. "Abortion: No Lasting Emotional Scars." Psychology Today 8 (November 1974).

Ekblad, N. "Induced Abortion on Psychiatric Grounds." Acta Psychiatrica Scandinavica (1955). Supplement 99.

Freeman, Ellen W. "Abortion Beyond Rhetoric to Access." Social Work (November 1976).

Harrison, Colleen P. "Teenage Pregnancy--Is Abortion the Answer?" The Pediatric Clinics of North America 16.

Kahan, R. S.; Baker, L. D.; and Freeman, M. G. "The Effect of Legalized Abortion on the Morbidity of Criminal Abortion." American Journal of Obstetrics and Gynecology 121 (January 1975).

Knowles, J. H. "Public Policy on Abortion." Society 11 (July 1974).

Kummer, Jerome M. "Post Abortion Psychiatric Illness--A Myth?" The American Journal of Psychiatry 119 (April 1963) : $980-3$.

"Lesislators Agree to Limit Abortion Under Medicaid." Los Angeles Times, Washington Post Service, 16 September 1976.

Levine, Howard, and Pugney, Francis. "Law, Preventative Psychiatry and the Therapeutic Abortion." The Journal of Nervous and Mental Disease 151.

Malo-Juvera, Delores. "What Pregnant Teenagers Know about Sex." Nursing Outlook 18 (November 1970).

Nathe, William M., and Lacefield, Ike R. "Degree of Depression in Women Preceding Abortion at the University of Oregon Medical School." Graduate School of Social Work, Portland State University Graduate School of Social Work, 23 February 1972.

Oregon State Health Department. "Induced Abortions." Oregon State Health Department, Vital Statistics, March 1976 . 
Overstreet, Edmond W. "california's Abortion Law--A Second Look." In Abortion and the Unwanted Child. Edited by Carl Reiterman. Springer Publishing Co., Inc., 1971.

Roemer, R. "Abortion Law Reform and Repeal: Legislative and Judicial Developments." American Journal of Public Health 61 (March 1971).

Rossi, Alice S. "Abortion Laws and Their Victims." Transaction (Sept.-Oct. 1966).

Simon, Nathan; Senturia, Audrey; and Rothman, David. "Psychiatric Illness Following Therapeutic Abortion." The American Journal of Psychiatry 124 (July 1967).

Spalding, Denise. "Abortions: Legal but How Available?" Ms., September 1975, pp. 103-6.

Tietze, C. "Mortality with Contraception and Induced Abortion." In A Study of Family Planning, vol. 45.

Walters, G. G. "Psychological and Emotional Consequences of Elective Abortion: A Review." Obstetrics and Gynecology 36 (September 1970):482-91.

Weinstock, Edward; Teitze, C.; Jaffe, F.; and Dryfoos, J. "Abortion Need and Services in the United States, 1974-75." Family Planning Perspectives 8 (March/ April 1975):58-9. 
APPENDIX 
We are graduate students at Portland State School of Social Work. As a part of our graduate requirement, we are doing a research study to try and determine some of the needs of women going through abortion. We chose this area because we are both interested in the concerns and needs of all women. We appreciate the support and cooperation Lovejoy Specialty Hospital has given us. In addition we would like to thank you for taking the time to participate in our study.

Please answer every question. To insure complete confidentiality, do not write your name on the questionnaire. If you are interested in the results of this study please feel free to call us some time early next year. We will both be able to be reached at Portland State School of Social Work.

Thank you so much,

S/Wendy Green

and

S/Susie Milberg 


\section{QUESTIONNAIRE}

1. What is your age?

2. What is your occupation?

3. Check the space which most closely describes your education. (check one)

a. 8th grade - 11th grade

b. 12th grade or high school graduate

c. Jr. college

d. Business or trade school

e. Four year college

f. Graduate school

g. Other (please specify)

4. Do you attend or plan to attend school in the coming year?

yes

no

5. What was your living arrangement when you found out you were pregnant?

$$
\begin{aligned}
& \text { ( ) }) \text { a. Living alone } \\
& \text { ( }) \text {. Living with parents } \\
& \text { ( }) \text { diving with friend(s) } \\
& \text { d. Living with mate } \\
& \text { e. Other (please specify) }
\end{aligned}
$$

6. Do you have any children?

yes

no

IF YES :

how many?

what are their ages?

7. When you found out you were pregnant was there a person(s) you could confide in?

yes

no 
8. After going through this abortion experience, do you: (check as many as you want)

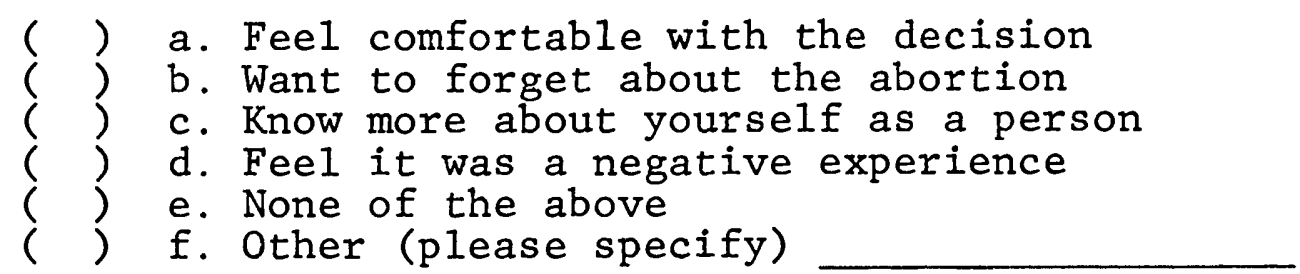

9. If the following services were available to you, would you use: (please check as many as you want)

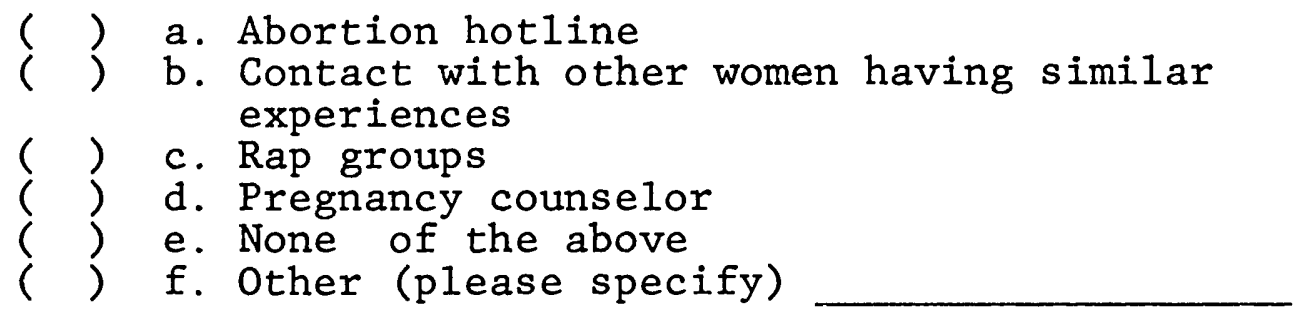

10. Prior to your pregnancy did you have information about birth control methods?

yes no

IF YES: Where did you get it? (check the one main source)

$$
\begin{aligned}
& \text { ( ) a. Friends } \\
& \text { ( }) \text { c. Family doctor } \\
& \text { c. Planned Parenthood or family } \\
& \text { ( ) d. Family } \\
& \text { ( }) \text { e. School } \\
& \text { ( }) \text { Books, magazines, newspapers, T.V. } \\
& \text { g. Other (please specify) }
\end{aligned}
$$

11. Do you feel confident in your present knowledge concerning birth control methods?

yes

no 
12. Think about the time when you found out you were pregnant. Which of the following options did you know enough about to personally consider using?
( ) a. Abortion
( ) b. Continuing pregnancy and giving up child for adoption
( ) c. Continuing pregnancy and becoming a single parent
( ) d. Continuing pregnancy within present family unit
( ) e. Continuing pregnancy and forming a family unit with or without marriage
( ) f. Other (please specify)

13. If you knew about abortion as an alternative to pregnancy, where did you get the information?
( ) a. School
( ) c. Friends
( ) d. Books, magazines, newspapers, T.V.
( ) e. Family doctor
( ) f. Planned Parenthood or family planning
( ) h. Religious organization

14. If you did have information on abortion, was it difficult to obtain?

yes no

IF YES: What made it difficult?

15. How did you hear about Lovejoy Specialty Hospital?

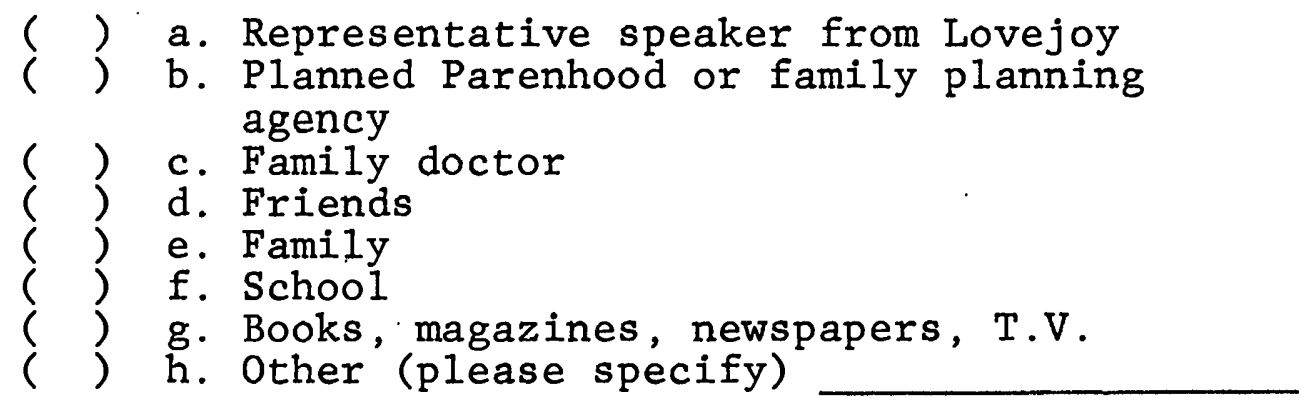


16. Did you have difficulty paying for your abortion?

yes no

IF YES: How did you handle it?

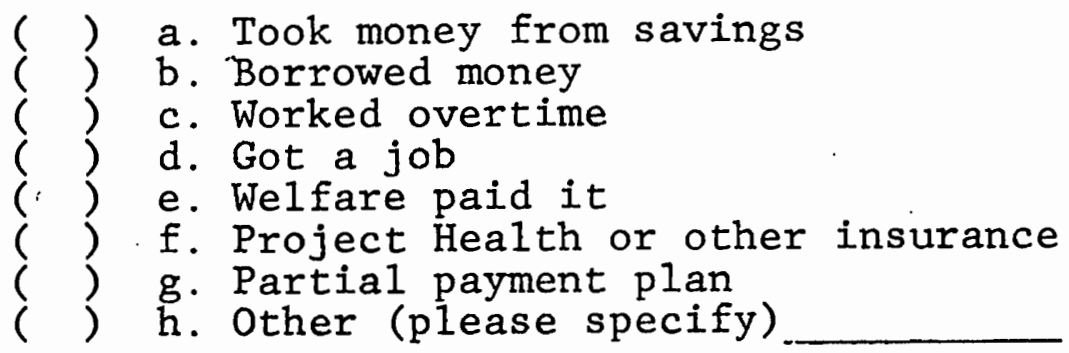

